\title{
"Ormocer an innovative technology": A replacement for conventional cements and veneer? A comparative in vitro analysis
}

\author{
Vini Rajeev ${ }^{1}$, Rajeev Arunachalam ${ }^{2}$, Sanjna Nayar ${ }^{3}$, P. R. Arunima ${ }^{4}$, Sivadas Ganapathy ${ }^{5}$,
} Vaishnavi Vedam ${ }^{6}$

Correspondence: Dr. Vini Rajeev

Email: vinirajeev09@gmail.com

\author{
'Department of Prosthodontics, AIMST University, \\ Kedah, Malaysia, \\ ${ }^{2}$ Department of Periodontics, AIMST University, Kedah, \\ Malaysia, \\ ${ }^{3}$ Department of Prosthodontics, Sree Balaji Dental \\ College and Hospital, Chennai, Tamil Nadu, India, \\ ${ }^{4}$ Department of Periodontics, PMS Dental College, \\ Thiruvananthapuram, Kerala, India, \\ ${ }^{5}$ Department of Pedodontics, AIMST University, Kedah, \\ Malaysia, \\ ${ }^{6}$ Department of Oral Pathology, AIMST University, \\ Kedah, Malaysia
}

\section{ABSTRACT}

Objective: This in vitro study was designed to assess shear bond strength (SBS) of ormocer flowable (OF) resin as a luting agent, ormocer as an indirect veneer material with portrayal of modes of failures using scanning electron microscope (SEM). Materials and Methods: Sixty maxillary central incisors were divided into Group I, II, and III with 20 samples each based on luting cement used. They were OF, self-adhesive (SA) cement, and total etch (TE) cement. These groups were subdivided into "a" and " $b$ " of ten each based on the type of veneering materials used. Veneer discs were fabricated using Ormocer restorative $(\mathrm{O})$ and pressable ceramic $(\mathrm{C})$. Specimens were thermocycled and loaded under universal testing machine for SBS. The statistical analysis was done using one-way ANOVA post hoc Tukey honest significant difference method. Results: A significant difference was observed between the Groups I and II $(P<0.05)$. The highest mean bond strength when using ormocer veneer was obtained with the Group Ia $(19.11 \pm 1.92 \mathrm{Mpa})$ and lowest by Group IIa $(8.1 \pm 1.04 \mathrm{Mpa})$, whereas the highest mean bond strength while using ceramic veneer was of similar range for Group Ib (18.04 $\pm 4.08 \mathrm{Mpa})$ and Group IIIb $(18.07 \pm 1.40 \mathrm{Mpa})$. SEM analysis revealed OF and TE presented mixed type of failure when compared with SA where failure mode was totally adhesive. Conclusion: OF was found equally efficient like TE. Bond strength of ormocer as a veneer was not inferior to ceramic making it one of the promising additions in the field of dentistry.

Key words: Adhesive dentistry, luting cements, ormocer, shear bond strength

\section{INTRODUCTION}

Advances in adhesive dentistry made the clinicians to explore the capacity of dental cements bondage

\begin{tabular}{|l|l|}
\hline \multicolumn{2}{|c|}{ Access this article online } \\
\hline Quick Response Code: \\
\hline
\end{tabular}

This is an open access article distributed under the terms of the Creative Commons Attribution-NonCommercial-ShareAlike 3.0 License, which allows others to remix, tweak, and build upon the work non-commercially, as long as the author is credited and the new creations are licensed under the identical terms.

For reprints contact: reprints@medknow.com

How to cite this article: Rajeev V, Arunachalam R, Nayar S, Arunima PR, Ganapathy S, Vedam V. "Ormocer an innovative technology": Areplacement for conventional cements and veneer? A comparative in vitro analysis. Eur J Dent 2017;11:58-63.

DOI: 10.4103/ejd.ejd_113_16 
with tooth structure; assuring restorations with better retention, marginal adaptation, and reduced microleakage. Perpetual preservation of tooth structure inspired clinicians to use laminate veneers for fulfilling esthetic demand of patients. Lineage of materials for indirect veneering started with ceramics progressed to composites. The empress 2 ceramic system derives its strength and esthetics from hot pressing a lithium disilicate glass-ceramic framework veneered with flourapatite ceramic. ${ }^{[1]}$ The cost, time, ${ }^{[2]}$ low repair potential, and difficulty in intraoral polishing ${ }^{[3]}$ are setbacks of ceramic restorations. Hikita et al. reported that indirect composites exhibit better expediency, marginal integrity, and reduced polymerization shrinkage. ${ }^{[4]}$

Technology combining glass-like component with polymer resulted in ormocer the organically modified ceramic with hardness as glass and properties of resin. ${ }^{[5,6]}$ This tooth-colored material available in restorative and flowable form presents improved esthetics, biocompatibility, high abrasion resistance, reduced polymerization shrinkage, decreased surface roughness, and protection against caries. ${ }^{[1,5]}$ Ormocer overcame the concerns regarding estrogenicity and cytotoxicity associated with bisphenol A-glycidyl methacrylate-based composites. ${ }^{[7,8]}$ Ormocer has inorganic silicon dioxide foundation to which polymerized organic units are added with methacrylate substituted $\mathrm{ZrO}_{2}$ and $\mathrm{SiO}_{2} \cdot{ }^{[9-11]}$ Gold standard for assessing the clinical efficacy of any restorative material is by evaluating shear bond strength (SBS) and limited studies are reported till date with regard to restorative and flowable type of ormocer. Henceforth, this study was aimed to determine the efficiency of ormocer pertaining to adhesion and veneering.

\section{MATERIALS AND METHODS}

\section{Sample collection}

Sixty intact maxillary central incisors were collected, sterilized, and were divided into three equal groups (Group I, II, and III) based on luting agents used. The three groups were further divided into subgroups $(a, b)$ of 10 each based on type of veneering material used.

Group 1: Samples luted with ormocer flowable (OF) (Admira flowable, Voco, Germany)

Group II: Samples luted with self-adhesive (SA) cement (RelyX U100, 3M, USA)
Group III: Samples luted with total etch (TE) adhesive (Calibra, Dentsply, USA)

Subgroup a: Veneer discs made from ormocer $(\mathrm{O})$ restorative (Admira, Voco, Germany)

Subgroup b: Veneer discs made from ceramic (C) (E-max, Ivoclar, Lichenstein)

These samples were mounted on acrylic resin blocks and kept in distilled water for $24 \mathrm{~h}$ to prevent drying of the sample.

\section{Preparation of veneer discs}

A stainless steel metal plate with hole of $5 \mathrm{~mm}$ diameter and $2 \mathrm{~mm}$ thickness was prepared for fabricating veneer discs. Ceramic discs were prepared by flowing wax patterns (Bego, Germany) into the circular opening of the metal plate. After burned out (EP600 Combi, Ivoclar vivadent, Liechtenstein), the ingots were pressed in the mold with a plunger at $700^{\circ} \mathrm{C}$ and raised to $930^{\circ} \mathrm{C}$. The ormocer veneers were fabricated by packing the material into the circular opening of the metal mold. Light curing (Surident, India) was done for $40 \mathrm{~s}$ and the discs were retrieved followed by finishing, polishing, and verification of the dimension using a calliper.

\section{Surface treatment of bonding surfaces}

Labial surface of enamel was made flat in center using diamond points. Surface was polished and etched with $37 \%$ phosphoric acid for 15 s (Amdent, PA, USA) for Group I and III.

The bonding surface of ceramic discs was etched with 9.6\% hydrofluoric acid (Ultradent, South Jordan) for $1 \mathrm{~min}$, washed and dried for $15 \mathrm{~s}$ with air syringe. Single coat of silane coupling agent (RelyX ceramic primer, 3M ESPE, MN, USA) was applied and kept undisturbed for $1 \mathrm{~min}$ before cementation.

\section{Cementation of the veneer discs}

Teflon tube of inner diameter $5 \mathrm{~mm}$ and length $5 \mathrm{~mm}$ connected to two parallel support rods was used for conforming discs in position on tooth while cementation. A thin metal rod of $4 \mathrm{~mm}$ diameter was inserted into the Teflon tube while discs are in position for aiding in cementation. After stabilizing the specimen, a static load of $5 \mathrm{~kg}$ was applied for $1 \mathrm{~min}$ on the other end of the rod during cementation, and then, light curing was done at $400 \mathrm{~mW} / \mathrm{cm}^{2}$ for $40 \mathrm{~s}$ on all sides of the disc.

For Group I, single coat of bonding agent Admira bond was applied on etched enamel surface for $15 \mathrm{~s}$ 
and on veneering surface of discs. It was air dried and light cured for $10 \mathrm{~s}$. OF of $2 \mathrm{~mm}$ was directly dispensed on veneer discs and cemented by light curing.

For Group II, $2 \mathrm{~mm}$ of base and catalyst pastes of SA cement were dispensed from clicker onto mixing pad and was mixed thoroughly. After mixing, it was applied on the veneering surface of the discs and were placed on prepared tooth surface and luted in previously described manner.

For Group III, the bonding agent (Prime and bondNT Dentsply, Milford, USA) was applied on the etched enamel and veneer surface for $15 \mathrm{~s}$. Then, it was air dried for $3 \mathrm{~s}$ and light cured. $2 \mathrm{~mm}$ base and catalyst paste of TE cement were dispensed and mixed. The mixture was evenly applied on the veneering surface discs and cemented by light curing.

\section{Testing procedure}

The specimens kept in distilled water were thermocycled for 5000 cycles between $5^{\circ} \mathrm{C}$ and $55^{\circ} \mathrm{C}$ with dwelling time of $15 \mathrm{~s}$ after which the shear bond testing procedures were carried out using the Universal testing machine (Lloyd, UK) by loading the samples vertically. Compressive mode of load was applied at the core-veneer interface using a monobeveled metal chisel attached to the upper movable compartment of the machine travelling at crosshead speed of $2 \mathrm{~mm} / \mathrm{min}$. Sudden drop along the load-deflection curve at displacement of discs was recorded. The SBS was calculated using the formula $\delta=P / \pi r^{2}$ where $\delta$ is SBS (MPa), $P$ is load at failure $(N)$, $r$ is radius of disc $(1 \mathrm{~mm})$.

After shear bond testing procedure, one sample from each group was selected randomly for scanning electron microscope (SEM) analysis (Hitachi S3000N, Japan). The tooth was sectioned at the cementoenamel junction using carborundum disc. The coronal portion of the teeth and its corresponding veneers were gold sputtered for conduction of radiation. The section of tooth and veneer were observed under microscope to assess the mode of failure at a magnification of $\times 500$.

\section{RESULTS}

The results obtained for groups along with subgroups are presented in Tables 1-4. Figure 1 represents bar diagram showing the comparison of SBS of three luting cements with ormocer and ceramic veneers. SEM photographs of the specimens showing the mode of failure and micrometric spaces are depicted in Figures 2-5.

\begin{tabular}{|c|c|c|c|c|}
\hline & \multirow{3}{*}{$\begin{array}{c}\text { Subgroup } \\
\text { a (O) }\end{array}$} & \multirow{3}{*}{$\begin{array}{c}\text { Subgroup } \\
\text { b (C) }\end{array}$} & \multirow{2}{*}{\multicolumn{2}{|c|}{ SD }} \\
\hline & & & & \\
\hline & & & $\begin{array}{c}\text { Subgroup } \\
\text { a (0) }\end{array}$ & $\begin{array}{c}\text { Subgroup } \\
\text { b (C) }\end{array}$ \\
\hline Group I (OF) & 19.1680 & 18.4020 & 1.92967 & 4.08507 \\
\hline Group II (SA) & 8.1800 & 10.8860 & 1.04770 & 3.36584 \\
\hline Group III (TE) & 17.8120 & 18.0760 & 4.38071 & 1.40791 \\
\hline
\end{tabular}

SD: Standard deviation, SA: Self-adhesive cement, TE: Total etch cement, OF: Ormocer flowable

\begin{tabular}{|c|c|c|c|}
\hline Group (I) & Group (J) & Mean difference & Significant \\
\hline \multirow[t]{2}{*}{$\overline{\mathrm{OF}}$} & SA & $10.98800^{*}$ & 0.000 \\
\hline & TE & 1.35600 & 0.539 \\
\hline \multirow[t]{2}{*}{ SA } & OF & $-10.98800^{*}$ & 0.000 \\
\hline & TE & $-9.63200^{*}$ & 0.000 \\
\hline \multirow[t]{2}{*}{ TE } & OF & -1.35600 & 0.539 \\
\hline & SA & $9.63200^{*}$ & 0.000 \\
\hline
\end{tabular}

*The mean difference is significant at 0.05 level. SA: Self-adhesive cement, TE: Total etch cement, OF: Ormocer flowable

\begin{tabular}{|c|c|c|c|}
\hline Group (I) & Group (J) & Mean difference & Significant \\
\hline \multirow[t]{2}{*}{ OF } & SA & $7.51600^{*}$ & 0.000 \\
\hline & TE & 0.32600 & 0.971 \\
\hline \multirow[t]{2}{*}{ SA } & OF & $-7.51600^{*}$ & 0.000 \\
\hline & TE & $-7.19000^{*}$ & 0.000 \\
\hline \multirow[t]{2}{*}{ TE } & OF & -0.32600 & 0.971 \\
\hline & SA & $7.19000^{*}$ & 0.000 \\
\hline
\end{tabular}

\begin{tabular}{|c|c|c|c|}
\hline & $\begin{array}{c}\text { Adhesive failure from } \\
\text { tooth surface }(\%)\end{array}$ & $\begin{array}{c}\text { Cohesive } \\
\text { failure (\%) }\end{array}$ & $\begin{array}{c}\text { Mixed } \\
\text { failure (\%) }\end{array}$ \\
\hline Group la & 30 & 20 & 50 \\
\hline Group Ib & 20 & 10 & 70 \\
\hline Group Ila & 70 & 0 & 30 \\
\hline Group IIb & 80 & 0 & 20 \\
\hline Group IIla & 20 & 20 & 60 \\
\hline Group IIIb & 20 & 10 & 70 \\
\hline
\end{tabular}

The statistical analysis was performed using appropriate tests. The data were interpreted at a confidence interval of $95 \%$. ANOVA was used to compare the SBS values of three resin luting agents 


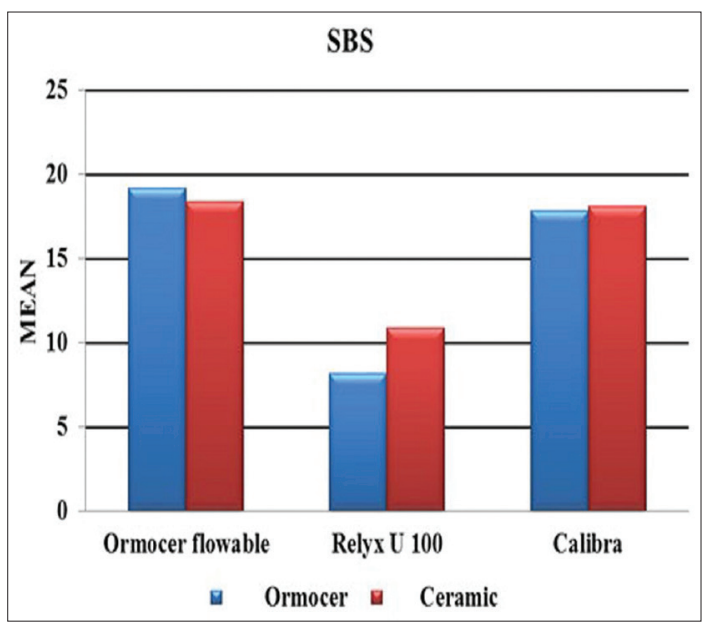

Figure 1: Represents bar diagram showing the comparison of shear bond strength of three luting cements with ormocer and ceramic veneers

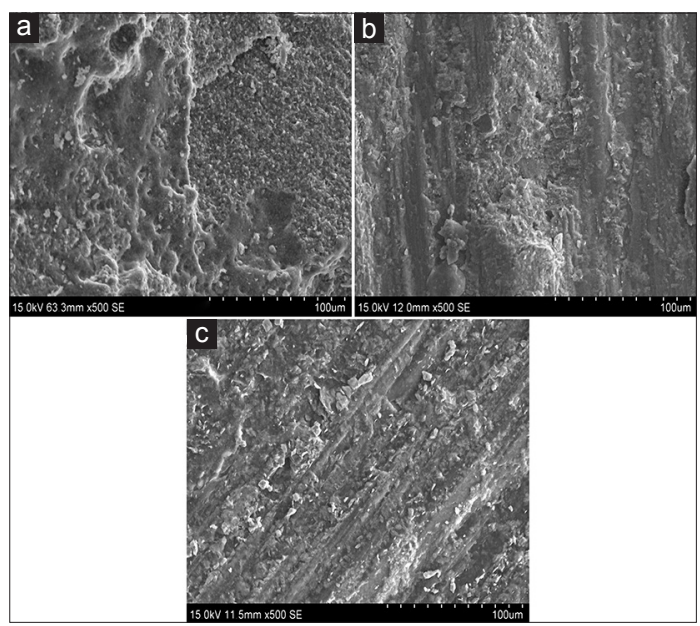

Figure 3: (a-c) Show cohesive failure of the cement while using ormocer cement. The tooth (a), the ormocer veneer surface (b), and ceramic veneer surface (c) show cement remnants after the bond strength test

used for the cementation of the indirect veneers in this study. Post hoc Tukey honest significant difference method was used for multiple comparisons of the luting agents and the veneers.

A significant difference was observed between Group I and II $(P<0.05)$. Highest mean bond strength when using ormocer veneer was obtained with the Group Ia $(19.11 \pm 1.92 \mathrm{Mpa})$ followed by Group IIIa (17.8 $\pm 4.38 \mathrm{Mpa})$ and Group IIa $(8.1 \pm 1.04 \mathrm{Mpa})$, whereas the highest mean bond strength when using ceramic veneer, the values are of similar range for Group $\mathrm{Ib}(18.04 \pm 4.08 \mathrm{Mpa})$ and Group IIIb $(18.07 \pm 1.40 \mathrm{Mpa})$ followed by Group IIb (10.8 $\pm 3.36 \mathrm{Mpa})$.Group IIa and IIb showed statistically lower bond strength in comparison with other groups. The comparison of OF and TE cement

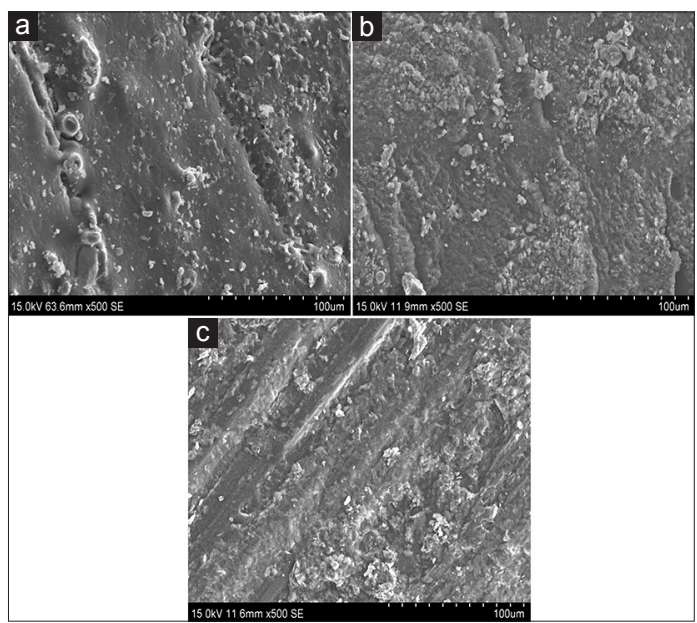

Figure 2: (a-c) Show mixed failure of the cement while using ormocer cement. (a) Shows the enamel surface, (b) shows the ormocer veneer surface, and (c) shows the ceramic veneer surface. The micrometric spaces created on the surface of tooth and veneer after etch and bond procedures can be visualized

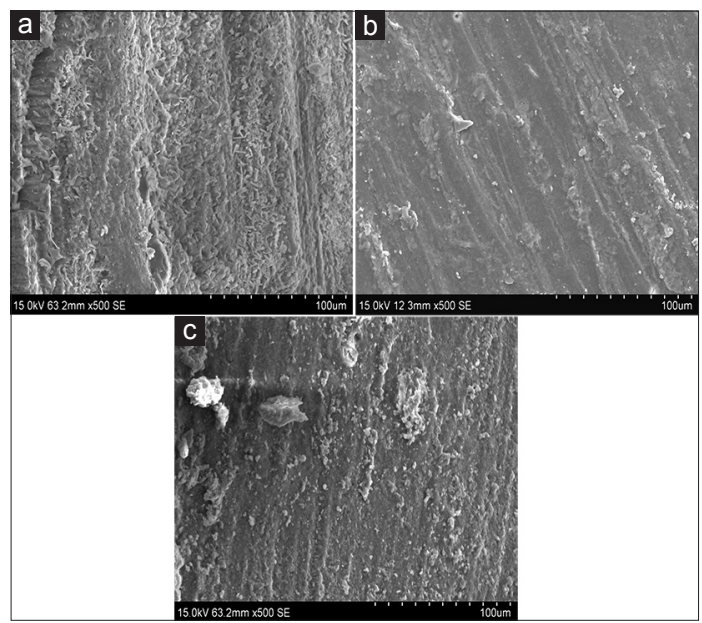

Figure 4: (a-c) Show adhesive failure from the tooth surface on using ormocer cement. The tooth (a) did not show remnants of cement whereas the ormocer veneer surface (b) ceramic veneer surface (c) shows cement remnants after the bond strength test

did not present a statistical difference. In SEM study, Group I and Group III samples showed predominantly mixed type of failure. Group II samples showed mostly adhesive type of failure from the tooth surface.

\section{DISCUSSION}

In the dynamic oral environment, stresses at interface of restorations are complex and primarily are of shear type. Hence, SBS test can be used to assess quality of adhesive resin cement. ${ }^{[12]}$ Frankenberger et al. advocated the use of flowable composites as adhesive cement. ${ }^{[13]}$ The acidic monomers in resin cements remove the smear layer causing inward diffusion of comonomers into the etched enamel and 


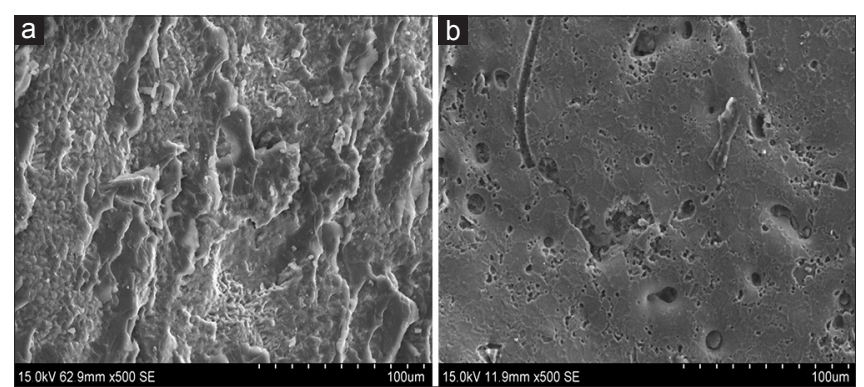

Figure 5: ( $a$ and $b$ ) Show the micrometric spaces on tooth surface that received total etch cement (a) and that received self-adhesive cement (b)

dentin by resin tag formation and form the hybrid layer thereby promoting bond to tooth structure. ${ }^{[14-16]}$

The success of resin cements with ceramic veneer can be attributed to the fact that resin-based material reduces the potential for crack propagation by sealing Griffith flaws. ${ }^{[17]}$ The polymerization shrinkage of the resin helps in strengthening porcelain by exerting a force on the inner surface of the ceramic. This causes the movement of porcelain molecules together rather than away from each other. ${ }^{[18]}$ Leucite crystal dissolution occurs during the etching of ceramic surface with hydrofluoric acid leading to the formation of microcavities on the surface ${ }^{[19]}$ resulting in highly retentive surface to silane coupling agent and adhesives. The application of a silane coupling agent to the pretreated ceramic surface provides a chemical covalent and hydrogen bond and it is a major factor for a sufficient bond between resin and ceramics. ${ }^{[16,20]}$

The filler particle size for ormocer restorative is about 0.04-0.7 $\mu \mathrm{m} .{ }^{[8]}$ Better retention and bond strength of ormocer as indirect laminate veneers may be due to progressively decreasing filler particle size that aids in better dispersion and increased interfacial area between the matrix and filler. ${ }^{[21]}$

OF composite showed relatively higher bond strength when compared to SA system. The reduction in filler particle size and addition of diluent monomers reduces film thickness and increases bond strength favoring flowable type as luting cement. OF is a light-curing restorative material with good flowability and high material elasticity making them appropriate stress-absorbing material, particularly when used with ormocer restorative.

In the present study, the SA cement showed the lowest mean bond strength which is in agreement with other studies. ${ }^{[21]}$ The SA cement in the present study is methacrylate based having a strong acidic condition with a $\mathrm{pH}$ of 1.5-2.5 range during initial mixture where esters such as HEMA, TEGDMA, or HEMA-phosphate are hydraulically degraded. ${ }^{[15]}$ This could be a reason for the decreased bond strength of SA cements over ormocer veneers as it also contains dimethacrylates. Bond strength also depends on surface flaws. ${ }^{[19]}$ Ormocer veneer have less surface roughness of $0.132 \mathrm{~mm},{ }^{[8]}$ and hence, lesser surface flaws. The amount of reduced roughness and the absence of etch and bond procedures in SA cement could have led to reduced bond strength.

Studies have shown that acid etching of ceramic surface causes precipitation of residual subproducts composed of fluorosilicates of $\mathrm{Al}, \mathrm{K}, \mathrm{Na}$, and $\mathrm{Ca}$ on the ceramic surface. This gets deposited in the interface of the restoration and the cement resulting in a change in the wetting and infiltration dynamics. This results in reduction of ceramic-composite bond strength and is one of the prime causes for the lower bond strength of ceramic to self-etch SA cement compared to other cements used in the study. ${ }^{[19]}$ Nevertheless, it can be concluded that the better bonding of the ceramic veneer with SA cement could be due to the micromechanical retention and chemical interaction between the monomer acidic phosphate groups and hydroxyapatite. ${ }^{[14,16,21]}$

From the current study, it could be demonstrated that the OF utilizing the ormocer technology is as effective as the TE cement. OF which is used for the restoration of carious teeth can also be used as a luting agent according to the present study and is available in different shades.

Tests used to evaluate bond strength of resin cements are not without limitations. The veneer discs were cemented to flat surface, and there can be unrestricted shrinkage of the resin cement even though various studies promise on reduced polymerization shrinkage. In clinical circumstances, there will be factors which can impair the bonding effectiveness of the luting agent. To judge the clinical relevance of the present in vitro testing method, a correlation with a long-term in vivo study should be carried out using the same materials.

\section{CONCLUSION}

Within the limitations of this study, the following conclusions were drawn: SBS of OF type was significantly higher than that of the SA resin. SEM analysis showed that mixed failure was predominant in OF type compared to others. Even though the bond 
strength of the ormocer was not inferior to ceramic, more studies are needed to be recommended as an effective restorative material.

\section{Financial support and sponsorship Nil.}

\section{Conflicts of interest}

There are no conflicts of interest.

\section{REFERENCES}

1. Akgungor G, Akkayan B, Gaucher H. Influence of ceramic thickness and polymerization mode of a resin luting agent on early bond strength and durability with a lithium disilicate-based ceramic system. J Prosthet Dent 2005;94:234-41.

2. Griggs JA. Recent advances in materials for all-ceramic restorations. Dent Clin North Am 2007;51:713-27, viii.

3. Clifford M. Sturdevant. Sturdevant's Art and Science of Operative Dentistry. $4^{\text {th }}$ ed. Mosby, Orlando,Florida,USA; 2002.

4. Hikita K, Van Meerbeek B, De Munck J, Ikeda T, Van Landuyt K, Maida $\mathrm{T}$, et al. Bonding effectiveness of adhesive luting agents to enamel and dentin. Dent Mater 2007;23:71-80.

5. Erdilek D, Dörter C, Koray F, Kunzelmann KH, Efes BG, Gomec Y. Effect of thermo-mechanical load cycling on microleakage in class II ormocer restorations. Eur J Dent 2009;3:200-5.

6. Taher NM. Comparative study of composite, compomers and ormocer biaxial flexural strength. Saudi Dent J 2002;14:7-10.

7. Kumar KS, Rao CH, Reddy KB, Chidambaram S, Girish H, Murgod S. Flowable composite an alternative orthodontic bonding adhesive: An in vitro study. J Contemp Dent Pract 2013;14:883-6.

8. Saunders SA. Current practicality of nanotechnology in dentistry. Part 1: Focus on nanocomposite restoratives and biomimetics. Clin
Cosmet Investig Dent 2009;1:47-61.

9. Sivakumar A, Valiathan A. Dental ceramics and ormocer technologynavigating the future. Trends Biomater Artif Organs 2006;20:40-3.

10. Ajlouni R, Bishara SE, Soliman MM, Oonsombat C, Laffoon JF, Warren J. The use of ormocer as an alternative material for bonding orthodontic brackets. Angle Orthod 2005;75:106-8.

11. Celik C, Yuzugullu B, Erkut S, Yamanel K. Effects of mouth rinses on color stability of resin composites. Eur J Dent 2008;2:247-53.

12. Holderegger C, Sailer I, Schuhmacher C, Schläpfer R, Hämmerle C, Fischer J. Shear bond strength of resin cements to human dentin. Dent Mater 2008;24:944-50.

13. Frankenberger R, Lopes M, Perdigão J, Ambrose WW, Rosa BT. The use of flowable composites as filled adhesives. Dent Mater 2002;18:227-38.

14. Pavan S, dos Santos PH, Berger S, Bedran-Russo AK. The effect of dentin pretreatment on the microtensile bond strength of self-adhesive resin cements. J Prosthet Dent 2010;104:258-64.

15. Moszner N, Salz U, Zimmermann J. Chemical aspects of self-etching enamel-dentin adhesives: A systematic review. Dent Mater 2005;21:895-910.

16. Anchieta RB, Rocha EP, de Almeida EO, Junior AC, Martini AP. Bonding all-ceramic restorations with two resins cement techniques: A clinical report of three-year follow-up. Eur J Dent 2011;5:478-85.

17. El Zohairy AA, Saber MH, Abdalla AI, Feilzer AJ. Efficacy of microtensile versus microshear bond testing for evaluation of bond strength of dental adhesive systems to enamel. Dent Mater 2010;26:848-54.

18. Roulet JF, Vanherle G. Adhesive Technology for Restorative Dentistry. Proceedings from $3^{\text {rd }}$ ed. European symposium on Adhesive Technology, Quintessence publishing company, Chicago, USA; 2005. p. 125.

19. Belli R, Guimarães JC, Filho AM, Vieira LC. Post-etching cleaning and resin/ceramic bonding: Microtensile bond strength and EDX analysis. J Adhes Dent 2010;12:295-303.

20. Blatz MB, Sadan A, Kern M. Resin-ceramic bonding: A review of the literature. J Prosthet Dent 2003;89:268-74.

21. Viotti RG, Kasaz A, Pena CE, Alexandre RS, Arrais CA, Reis AF. Microtensile bond strength of new self-adhesive luting agents and conventional multistep systems. J Prosthet Dent 2009;102:306-12. 